\title{
Comparison of Bone Marrow Concentrate, Non-Operative Care and Fusion for Discogenic Back Pain
} Kenneth A. Pettine ${ }^{1 *}$, D. Maxwell ${ }^{1}$

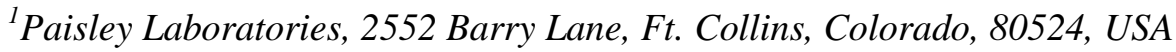

\begin{abstract}
Study Design: This paper compares 2 published studies on the results of treating discogenic back pain with bone marrow concentrate (BMC) to a systematic review on the results of lumbar fusion (20 studies) and nonoperative care (6 studies) for the same diagnosis.

Materials: 6 RCT papers comparing fusion to non-operative care met criteria. 12 RCT comparing fusion to fusion papers met criteria. 2 prospective non-randomized fusion papers met criteria. Fusion techniques included a combination of PLF, PLIF, TLIF, and ALIF.

Results: The improvement of ODI in the 20 surgical studies from pre-treatment to follow-up averaged $36.7 \%$, in the 6 non-surgical studies $17.5 \%$ and in the 2 BMC studies $64.7 \%$. The improvement in VAS in the surgical studies was $47.1 \%$, in the non-operative studies $20 \%$ and in the BMC studies $69 \%$. Overall satisfaction was $65.5 \%$ in the surgical studies, $55.6 \%$ in the non-operative studies and $67 \%$ in the BMC studies. The BMC studies had significantly better improvements in ODI and VAS vs. the surgical or non-operative studies. The overall cost was significantly less with the BMC treatment $(\$ 5,000)$ compared to surgery $(\$ 50,000$ to $\$ 75,000)$. Only 9 of the $172(5.2 \%)$ BMC patients had surgery vs. 24 of 130 (18.4\%) non-operative patients. The re-operation rate in the surgical studies was $11.7 \%$.

Conclusions: The use of bone marrow concentrate appears to be safe and efficacious. It may have advantages compared to surgery or non-operative care for the treatment of discogenic back pain.
\end{abstract}

Keywords: Mesenchymal Stem Cells; Stem cells; Cell-based therapy; Bone Marrow Concentrate; discogenic back pain

\section{Introduction}

The United States direct and indirect cost of discogenic back pain exceeds 100 billion dollars annually [1,2]. Non-operative treatments include weight loss, exercise, heat, ice, NSAIDs, chiropractic, physical therapy, acupuncture, oral steroids, steroid injections, and opiates $[3,4]$. The use of opiates to treat chronic low back pain is a major contributor to the current opioid crisis [5].

Surgical options for discogenic back pain are generally fusion. [6,7]. The lumbar fusion treatment for discogenic back pain has been evaluated by Phillips, et al. They published a systematic review of 26 studies comparing spinal fusion versus conservative care as well as studies comparing different fusion techniques for discogenic back pain [8].

The use of biologics to treat disc abnormalities is a nonsurgical option which can potentially bridge the gap between traditional non-surgical treatments for degenerative disc abnormalities and fusion surgery. There is mounting evidence to support the use of biologic and cell- based therapy for chronic discogenic low back pain. The authors of this paper have published one, two, three and five-year follow-up from a study assessing the safety and efficacy of bone marrow concentrate $[\mathrm{BMC}]$ cells as an alternative to surgery for discogenic back pain at one or two levels $[9,10,11,38]$. The authors have also published the results of treating multi-level discogenic back pain with BMC [35].

Corresponding Author: Kenneth Pettine M.D., Paisley Laboratories, 2552 Barry Lane, Ft. Collins, Colorado 80524 USA E-mail: ken@paisleylaboratories.com Received date: January 07, 2019; Accepted date: February 04, 2019; Published date: February 06, 2019.

DOI: https://doi.org/10.31546/JBRCI.1001 
There have been numerous studies utilizing mesenchymal stem cells to enhance tissue repair and decrease inflammatory damage in both in vitro lab studies and in vivo clinical models. It is known that BMC contains mesenchymal stem cells as well as a number of other cell types including but not limited to: hematopoietic stem cells, endothelial progenitor cells, and platelets. Studies have shown both the mesenchymal stem cell population and other nucleated cell types have healing properties and may contribute synergistically to the healing seen in studies on the spine $[19,20,21,22]$.

This is the first study to evaluate the clinical results of intradiscal BMC compared to lumbar fusion and nonoperative care for the treatment for discogenic low back pain.

\section{Materials and Methods Study Design}

This paper compared a prospective IRB and a second non-IRB (2 studies) non-randomized consecutive series of patients injected with BMC (class two data) to a systematic review on the results of lumbar fusion (20 studies) and non-operative care (6 studies). The patients enrolled as subjects in all these studies presented clinically with symptomatic moderate to severe discogenic back pain. Abnormalities were present on lumbar MRI scanning and plain radiographs. These abnormalities include anterior and posterior osteophyte formation, disc space narrowing on plain radiographs, and nucleus pulposus desiccation on MRI scanning $[23,36]$.

In all the studies the pre-treatment disability (ODI) $[24,25,26]$ had to be a minimum of $30 \mathrm{~mm} / 100 \mathrm{~mm}$ and pre-treatment baseline axial back pain had to be at least $40 \mathrm{~mm} / 100 \mathrm{~mm}$ on visual analog scale (VAS) 26 pain scores to meet inclusion criteria. All patients underwent a pre-treatment medical history and physical examination along with the ODI and VAS measurements. The ODI and VAS measurements were repeated at 24 months post injection of BMC, surgery, or non-operative care. The patients' primary physical complaint in the BMC study was one of axial central lumbar pain without leg pain. Standard exclusion criteria for the BMC and nonoperative studies included evidence of a symptomatic herniated disc. The Inclusion/exclusion requirements were similar in all the studies. The fusion studies accepted patients with a herniated disc and associated leg pain.

Materials and methods for the BMC study: This has been previously published [9].
Materials and Methods for the Fusion and Nonoperative studies:

Phillips et.al. published a systematic review of articles comparing fusion to non-operative care and fusion to fusion. This was accomplished by a search of the MEDLINE and Cochrane databases from 1950 through July of 2011 using the search terms outlined in Table 1 of their paper.

They identified 6 prospective randomized controlled studies (class 1 data) comparing fusion to non-operative results of treating discogenic back pain. The follow-up ranged from 12 to 48 months. The 6 non-surgical studies standard non-operative care was physical therapy or structured rehabilitation including exercise programs and/or cognitive interventions. They identified 12 prospective randomized controlled trials (class 1 data) comparing fusion to fusion.

The minimum follow-up on each surgical study was 24 months. They identified 2 prospective non-randomized studies (class 2 data) comparing fusion to fusion. Both with 24-month follow-up. Fusion techniques included a combination of PLF, PLIF, TLIF and ALIF. The data from each study was analyzed and placed into Table One. Microsoft Excel was utilized to compare the data between each group. Note, the averages in Table One are the means of the means from each study. Surgical complication rates could not be systematically summarized because of inconsistencies in reporting. Reoperation rate was evaluated as a somewhat more reliable measure of a negative outcome.

The average patient in the two BMC studies improved $64.7 \%$ in ODI and $69 \%$ in VAS. The baseline ODI averaged 41.1 which improved to 14.8 . The baseline VAS averaged 62.6 which improved to 19.7. The patients reported an overall satisfaction rate of $67 \%$ with the procedure and their clinical result. Only nine of the 172 BMC patients had surgery (5.2\%).

\section{Adverse Events in the BMC Studies}

There were no serious adverse events related to the BMC study. Most patients experienced transient pain at the aspiration and injection sites that typically resolved within 48 hours (aspiration site) to 7 days (injection site) following the procedure. No patient reported increases in VAS or ODI upon follow-up examination from their preprocedure values. 


\begin{tabular}{|l|c|c|c|c|c|c|}
\hline \multicolumn{1}{|c|}{ Measurement } & \multicolumn{2}{|c|}{$\begin{array}{c}\text { RCT surgery vs. non- } \\
\text { surgery- 6 studies }\end{array}$} & $\begin{array}{c}\text { RCT surgery vs. } \\
\text { surgery- 12 } \\
\text { studies }\end{array}$ & $\begin{array}{c}\text { Prospective } \\
\text { Non- } \\
\text { Randomized } \\
\text { - 2 Studies }\end{array}$ & $\begin{array}{c}\text { Weighted } \\
\text { Averages }\end{array}$ & BMC- 2 Studies \\
\hline Surgery/No Surgery & Surgery & $\begin{array}{c}\text { No } \\
\text { Surgery }\end{array}$ & Surgery & Surgery & & No Surgery \\
\hline \# of Patients & 547 & 372 & 1420 & 302 & & 172 \\
\hline Average Age & 41.5 & 41.3 & 42.6 & 46.3 & & 52.7 \\
\hline $\begin{array}{l}\text { Average Follow-up } \\
\text { months }\end{array}$ & 24 & 24 & 28 & 23.1 & & 15 \\
\hline \# of Levels Treated & 1 or 2 & NA & $\mathbf{1}$ or 2 & 1 or 2 & & 3.6 \\
\hline ODI \% Change & $29.0 \%$ & $17.5 \%$ & $25 \%$ & $26 \%$ & $36.7 \%$ & $64.7 \%$ \\
\hline VAS\% Change & $35.3 \%$ & $20.0 \%$ & $37 \%$ & $46 \%$ & $47.1 \%$ & $69 \%$ \\
\hline Satisfaction & $74.8 \%$ & $55.6 \%$ & $67.0 \%$ & $61 \%$ & $66 \%$ & $67 \%$ \\
\hline Reoperation & $7.0 \%$ & NA & $15.3 \%$ & Not Reported & & (Surgery 9 Patients) \\
\hline Fusion Rate & $84.0 \%$ & NA & $89.3 \%$ & $90 \%$ & & NA \\
\hline
\end{tabular}

Table 1: Comparison of Fusion, Non-operative Care, and Bone Marrow Concentrate. Clinical Results of BMC Patients: See Table 1.

\section{BMC Analytical Data and Imaging}

MRI imaging showed 8 out of 20 patients with imaging had at least a one grade improvement on the modified Pfirrmann grading scale for disc degeneration at one year [9]. No patient had a worse MRI score after one year. Patients with higher MSC concentration measured as CFU-F/ml tended to have better outcomes than those with lower concentrations.

Clinical Results of the Surgery Patients: See Table 1.

Six studies were RCT's comparing fusion to no surgery. The 547 surgery patients had an average ODI of 46.9 which improved to 33 (29\% change). They had an average VAS of 64.3 that improved to $41.5(35.3 \%$ change). Twelve RCT studies compared surgery to surgery. The 1420 fusion patients had a pre-procedure ODI of 52.1 that improved to 27.4 (47.2\% change). Their VAS went from 72.2 to 35.7 (43.3\% change). The two prospective non-randomized studies comparing different fusion techniques had 302 patients. Their ODI went from 46.8 to 19.9 ( $57.5 \%$ change). Their VAS went from 68.2 to 20 ( $70.2 \%$ change). The weighted averages of all the studies showed a $37 \%$ improvement in ODI, a $47 \%$ improvement in VAS and an average $66 \%$ satisfaction
Clinical Results of The Non-Operative Patients: See Table 1. There were 372 non-operative patients in the six RCT's comparing fusion to no surgery. Their ODI went from 46.2 to 38 (17.5\% change). Their VAS went from 58 to 47.4 (20\% change). They reported a $55.6 \%$ overall satisfaction rate with their non-operative care. The number of non-operative patients that went on to surgery was only reported in two of the six papers (130/372 patients). Twenty four of the 130 patients had surgery $(18.4 \%)$.

\section{Discussion}

This paper reviewed 22 published prospective studies comparing fusion, non-operative care and a BMC injection to treat discogenic low back pain. The BMC patients compared to the fusion and non-operative were slightly older (early 50's vs. early 40 's). Follow-up in the BMC studies was slightly less (15 vs. 24 months). The number of levels treated was more in the BMC studies ( 3.4 vs. 1 to 2 ). The improvement in ODI in the 20 fusion studies from pre-treatment to follow-up averaged $36.7 \%$, in the 6 non-surgical studies $17.5 \%$ and in the 2 BMC studies $64.7 \%$. The improvement in VAS in the fusion studies was $47.1 \%$, in the non-operative studies $20 \%$, and 
in the BMC studies $69 \%$. Overall satisfaction was $65.5 \%$ in the fusion studies, $55.6 \%$ in the non-operative studies and $67 \%$ in the BMC studies. The BMC studies had significantly better improvements in ODI and VAS vs. the surgical or non-operative studies. The overall cost was significantly less with the BMC treatment $(\$ 5,000)$ compared to fusion $(\$ 50,000$ to $\$ 75,000)$. Only 9 of the $172(5.2 \%)$ BMC patients had surgery vs. 24 of 130 (18.4\%) non-operative patients. The cross over to surgery data was only reported in 2 of the 6 non-operative studies. The re-operation rate in the fusion studies was $11.7 \%$.

Lumbar fusion is a very accepted surgical technique for the following conditions: spinal instability as with spondylolisthesis, progressive spinal deformities, infections and trauma. The clinical results of fusion in patients with these diagnoses is quite high. Lumbar fusion to treat discogenic back pain remains controversial [37]. This is especially true when the patient has no instability or leg symptoms or has multiple levels of degenerated discs [35].

The long term non-operative care of discogenic back pain patients is expensive and has not been shown to have a high success rate for significant improvements in ODI and VAS [12,13,14,15,16,17,18,27]. Opioids have been a mainstay of long term non-operative care. The results of this pharmacologic treatment have created a huge negative impact on patients and society $[28,29,30,31]$.

The interest in biologics to potentially bridge the gap between long term non-operative care and fusion surgery to treat discogenic back pain is increasing $[9,10,11,38]$.

Bone marrow concentrate is a source for mesenchymal stem cells. Mesenchymal stem cells have many positive attributes and have mounting evidence of safety and efficacy in human use [21,22,32,35]. MSCs are antiinflammatory, secrete numerous growth factors, stimulate blood vessel formation, modulate your immune system and can differentiate into cartilage cells to potentially help heal damaged discs [18,21,33,34]. Data supporting the use of mesenchymal stem cells to treat disc degeneration continues to increase.

Limitations of the two BMC studies include: Lack of randomization, lack of long term follow-up MRI scans and the lack of cell data in one of the studies.

\section{Conclusion}

This paper was a review comparing the results of fusion (20 studies), non-operative care (6 studies) and an injection of bone marrow concentrate (2 studies) for the treatment of discogenic back pain. The results showed significantly better improvements in ODI and VAS in the BMC studies. The BMC treatment cost was significantly less than surgery. Only $5.2 \%$ of the BMC patients went on to surgery vs. $18.4 \%$ of the non-operative patients. The re-operation rate was $11.7 \%$ in the fusion patients. Based on these results it may be reasonable to consider a bone marrow concentrate injection before undergoing fusion or even long term non-operative care for the treatment of discogenic back pain.

Acknowledgments: I would like to acknowledge the help of Dylan Meridith and Nick Collins in obtaining patient follow up

Funding: There was no outside funding for this research

\section{Conflict of interest: None.}

\section{References}

1. Katz JN. Lumbar disc disorders and low- back pain: socioeconomic factors and consequences. J Bone Joint Surg Am. 2006; 88: 21-24.

2.Dagenais S, Caro J, Haldeman S. A systematic review of low back pain cost of illness studies in the United States and internationally. Spine J. 2008;8:820.

3. Deyo RA, Weinstein JN. Low back pain. N Engl J Med. 2001;344:363-370.

4.Bydon M, De la Garza-Ramos R, Macki M, Baker A, Gokaslan AK, et al. Lumbar fusion vs. non-operative management for treatment of discogenic low backk pain: a systematic review and meta-analysis of randomized controlled trials. J Spinal Discord Tech. 2014;5:297-304.

5. White AP, Arnold PM, Norvell DC, Ecker E, Fehlings MG. Pharmacologic management of chronic low back pain: synthesis of the evidence. Spine (Phila Pa 1976). 2011;36:S131-143.

6. Chou R, Carragee JB, Eugene J, Resnick DK, Shaffer WO, et al. Surgery for Low Back Pain: A Review of the Evidence for an American Pain Society Clinical Practice Guideline Spine (Phila PA 1976). 2009;34:1094-1109.

7.Röllinghoff M, Schlüter-Brust K, Groos D, Sobottke R, Michael JW, et al. Mid-range outcomes in 64 consecutive cases of multilevel fusion for 
degenerative diseases of the lumbar spine. Orthop Rev (Pavia). 2010;2:e3.

8. Phillips FM, Slosar PJ, Youssef JA, et al. (2013) Lumbar spine fusion for chronic low back pain due to degenerative disc disease. Spine. 2013;38:E409-22.

9. Pettine K, Murphy M, Suzuki R, Sand T. Percutaneous injection of autologous bone marrow concentrate cells significantly reduces lumbar discogenic pain through 12 months. Stem Cells. 201533:146-156.

10. Pettine K, Suzuki R, Sand T, Murphy M. Treatment of discogenic back pain with autologous bone marrow concentrate injection with minimum twoyear follow-up. Int Orthop. 2016;40:135-140.

11. Pettine KA, Suzuki RK, Sand TT, et al. Autologous bone marrow concentrate intradiscal injection for the treatment of degenerative disc disease with three-year follow-up. Int Orthop. 2017;41(10):20972103. DOI: $10.1007 / \mathrm{s} 00264-017-3560-9$

12. Acosta F, Metz L, Adkisson H, Liu J, Liebenberg EC, et al. Porcine intervertebral disc repair using allogeneic juvenile articular chondrocytes or mesenchymal stem cells. Tissue Eng Part A. 2011;17:3045-3055.

13. Allon AA, Aurouer N, Yoo BB, Liebenberg EC, Buser Z, et al. Structured coculture of stem cells and disc cells prevent disc degeneration in a rat model. Spine J. 2010;10:1089-1097.

14. Feng G, Zhao X, Liu H, Zhang H, Chen X, et al. Transplantation of mesenchymal stem cells and nucleus pulposus cells in a degenerative disc model in rabbits: a comparison of 2 cell types as potential candidates for disc regeneration. J Neurosurgery Spine. 2011;14:322-329.

15. Ghosh P, Moore R, Vernon-Roberts B, Goldschlager $\mathrm{T}$, Pascoe D, et al. Immunoselected STRO-3+ mesenchymal precursor cells and restoration of the extracellular matrix of degenerate intervertebral discs. J Neurosurgery Spine. 2012;16:479-488.

16. Hee HT, Ismail HD, Lim CT, Goh JC, Wong HK. Effects of implantation of bone marrow mesenchymal stem cells, disc distraction and combined therapy on reversing degeneration of the intervertebral disc. J Bone Joint Surg Br. 2010;92:726-736
17. Hiyama A, Mochida J, Iwashina $\mathrm{T}$, Omi $\mathrm{H}$, Watanabe T, et al. Transplantation of mesenchymal stem cells in a canine disc degeneration model. J Orthop Res. 2008;26:589-600.

18. Sakai D, Mochida J, Iwashina $T$, Watanabe $T$, Nakai T, et al. Differentiation of mesenchymal stem cells transplanted to a rabbit degenerative disc model: potential and limitations for stem cell therapy in disc degeneration. Spine (Phila PA 1976). 2005;30:2379-2387.

19. Sakai D, Andersson GB. Stem cell therapy for intervertebral disc regeneration: obstacles and solutions. Nat Rev Rheumatol. 2015;11:243-256.

20. Yim R, Lee J, Bow C, Meij B, Leung V, et al. A systematic review of the safety and efficacy of mesenchymal stem cells for disc degeneration: Insights and future directions for regenerative therapeutics. Stem Cells Dev. 2014;23:2553-2567.

21. Murphy MB, Moncivais K, Caplan AI. Mesenchymal Stem Cells: environmentally responsive therapeutics for regenerative medicine. Exp Mol Med. 2013;45:e54.

22. Lalu MM, McIntyre L, Pugliese C, Fergusson D, Winston BW, et al. Safety of cell therapy with mesenchymal stromal cells (SafeCell): a systematic review and meta-analysis of clinical trials. PLoS One. 2012;7:e47559.

23. CW, Metzdorf A, Zanetti $\mathrm{M}$, et al. Magnetic resonance classification of lumbar intervertebral disc degeneration. Spine. 2001;26(17):1873-1878.

24. Yim R, Lee J, Bow C, Meij B, Leung V, et al. A systematic review of the safety and efficacy of mesenchymal stem cells for disc degeneration: Insights and future directions for regenerative therapeutics. Stem Cells Dev. 2014;23:2553-2567.

25. Fairbank JC, Pynsent PB. The Oswestry Disability Index. Spine. 2000;25(22):2940-2952.

26. Scott J, Huskisson EC. Vertical or horizontal visual analogue scales. Ann Rheum Dis 1979;38(6):560. doi.org/10.1136/ard.38.6.560

27. Dmitriev AE, Cunningham BW, $\mathrm{Hu} \mathrm{N}$, et al. Adjacent level intra-discal pressure and segmental kinematics following a cervical total disc 
arthroplasty: an in vitro human cadaveric model. Spine. 2005; 30:1165-1172.

28. Jeffrey Zeckser, Michael Wolff, Jason Tucker, and Josh Goodwin. Multipotent Mesenchymal Stem Cell Treatment for Discogenic Low Back Pain and Disc Degeneration. Stem Cells International. 2016; Article ID 3908389:13 pages.doi.org/10.1155/2016/3908389

29. Centeno, C., Markle, J., Dodson, E., Stemper, I., Williams, C., Hyzy, M.,Freeman, M. Treatment of lumbar degenerative disc disease-associated radicular pain with culture-expanded autologous mesenchymal stem cells: A pilot study on safety and efficacy. Journal of Translational Medicine. 2018;15:197. doi:10.1186/s12967-017-1300-y

30. Acosta, J., Frank L, Lotz, J., \& Ames, C. P. The potential role of mesenchymal stem cell therapy for intervertebral disc degeneration: A critical overview. Neurosurgical Focus. 2005;19(3),E4.

31. Hiyama A, Mochida J, Sakai D. Stem cell applications in intervertebral disc repair. Cell Mol Biol (Noisy-le-grand). 2008;54(1):24-32.

32. Peeters CM, Leijs MJ, Reijman M, van Osch GJ, Bos PK. Safety of intra-articular cell-therapy with culture-expanded stem cells in humans: a systematic literature review. Osteoarthritis Cartilage. 2013;21:1465-1473.

33. Counsel PD, Bates D, Boyd R, Connell DA. Cell therapy in joint disorders. Sports Health. 2015;7:27- 37 .

34. Kristjánsson B, Honsawek S. Current perspectives in mesenchymal stem cell therapies for osteoarthritis. Stem Cells Int. 2014;194318.

35. Pettine K A \& Santomaso T J. Treatment of Multilevel Discogenic Low Back Pain with Bone Marrow Concentrate. Stem Cell Res Th. 2017;2(1): 74-79.

36. Edgar MA. The nerve supply of the lumbar intervertebral disc. $\mathbf{J}$ Bone Joint Surg Br. 2007;89:1135-9.

37. Deyo RA, Gray DT, Kreuter W, et al. United States trends in lumbar fusion surgery for degenerative conditions. Spine. 2005;30:1441-5.

38. Pettine KA, Dordevic M. Reducing Lumbar Discogenic Back Pain and Disability with Intradiscal Injection of Bone Marrow Concentrate: 5-Year Follow-up. American Journal of Stem Cell Research. 2018;2(1):1-4. 